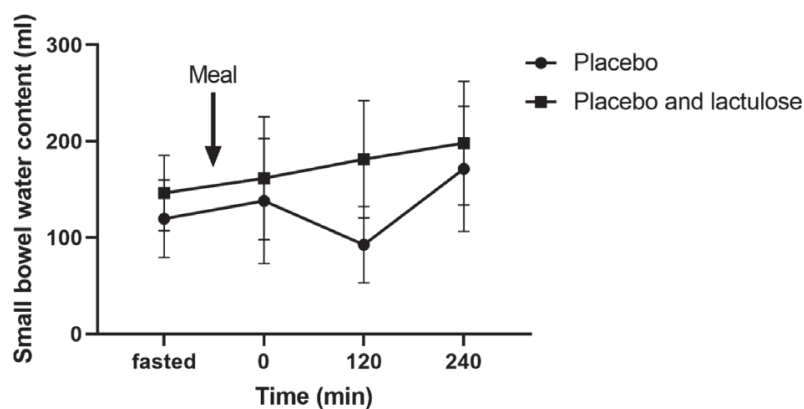

Abstract 055 Figure 1

hour versus 30.0 [17.0] 1.hour with no lactulose, $p=0.0078$ ) but had no effect on T1AC even after 36 hours treatment (0.74 [0.4]s versus $0.64[0.28] \mathrm{s}, p=0.72)$. Ondansetron did not significantly alter SBWC or T1AC, either after a meal alone or when combined with repeated doses of lactulose. Gut transit (median [IQR]), was unchanged by ondansetron compared to placebo $(1.7[0.5-5.8]$ versus 1.4 [0.5-6], $p=0.63)$.

Conclusions Although lactulose increases SBWC by an amount close to that predicted by its osmotic load $(130 \mathrm{ml})$ this did not significantly alter colonic water content. This may be due to its known rapid metabolism and suggests its laxative effect may be due to the stimulatory effects of products of fermentation. Ondansetron did not alter postprandial intestinal water nor reduce the effect of lactulose suggesting that its anti-diarrhoeal effect may be primarily due to altered colonic motility.

\section{O56 RISK FACTORS FOR PROXIMAL COLON CANCER: HOW INFORMATIVE ARE POLYP FINDINGS IN DETERMINING FUTURE RISK?}

${ }^{1}$ Rhea Harewood*, ${ }^{1}$ Kate Wooldrage, ${ }^{2} J a m e s$ Kinross, ${ }^{3}$ Christian von Wagner, ${ }^{1}$ Amanda J Cross. 'Cancer Screening and Prevention Research Group (CSPRG), Imperial College London, London, UK; ${ }^{2}$ Department of Surgery and Cancer, Imperial College London, London, UK; ${ }^{3}$ Research Department of Behavioural Science and Health, University College London, London, UK

\subsection{6/gutjnl-2020-bsgcampus.56}

Introduction Early detection and removal of premalignant colorectal polyps with a high potential to progress to invasive cancer is important for incidence reduction. However, there is evidence that cancers in the proximal colon tend to be detected later than other subsites resulting in more advanced stage at diagnosis and lower survival. This study examined which polyp characteristics were independently associated with proximal colon cancer incidence.

Methods Data were used from the All Adenomas study, which examined endoscopy and associated pathology data on $\sim 30,000$ individuals with at least one adenoma identified. Eligible participants underwent colonoscopy between 1984 and 2010 in one of 17 UK hospitals. Polyp characteristics at baseline colonoscopy, including number, size, histology, grade and location were obtained from the database. Cox regression models were used to estimate hazard ratios (HRs) and 95\% confidence intervals (CIs) for incidence of proximal colon adenocarcinoma. Time since baseline colonoscopy was used as the underlying time scale. HRs were mutually adjusted for polyp characteristics in addition to demographic- and colonoscopy-related confounders.

Results Of the 27,812 (42.4\% female) participants included in the analysis, $227(0.82 \%)$ developed proximal colon cancer during a median follow-up of 9 years. Cumulative incidence over 15 years was 1.4\% (95\% CI: 1.2\% - 1.6\%). Proximal colon cancer incidence was higher among participants with $\geq 1$ adenoma in the proximal colon at baseline, either solely or in addition to distal adenomas, compared to patients with only distal adenomas (HR 1.95, 95\% CI: 1.46 - 2.62). The risk was also higher among those with $\geq 3$ adenomas compared to those with $<3$ adenomas at baseline (HR 1.47, 95\% CI: 1.04 - 2.08) and those with adenomas $\geq 10 \mathrm{~mm}$ compared to those with adenomas $<10 \mathrm{~mm}$ (HR 1.47, 95\% CI: 1.07 - 2.01). Neither adenoma histology nor grade were independently associated with the outcome.

Conclusions Adenoma location, number and size are informative of subsequent proximal colon cancer. This study provides evidence needed to identify individuals at high risk for proximal colon cancer who would require post-polypectomy colonoscopy surveillance for the early detection and removal of cancer and precancerous lesions in this subsite.

\section{THE VALUE OF GERMLINE MUTATION TESTING IN SERRATED POLYPOSIS SYNDROME}

${ }^{1}$ Sujata Biswas*, ${ }^{1}$ Michael Johnson, ${ }^{1}$ Adam Bailey, ${ }^{1}$ Elizabeth Bird-Lieberman, ${ }^{1}$ Simon Leedham, ${ }^{2}$ Peter Risby, ${ }^{2} J o y c e$ Solomons, ${ }^{1} J a m e s$ East. ${ }^{1}$ Translational Gastroenterology Unit, Oxford NIHR Biomedical Research Centre, University of Oxford, Oxford, UK, UK; ${ }^{2}$ Oxford Centre for Genomic Medicine, Nuffield Orthopaedic Centre, Oxford University Hospitals NHS Foundation Trust, UK

\subsection{6/gutjnl-2020-bsgcampus.57}

Introduction Serrated Polyposis Syndrome (SPS) is now known to be the commonest polyposis syndrome. Previous analyses for germline mutations have shown no consistent positive findings ${ }^{1}$. To exclude other polyposis syndromes, new 2019 BSG guidelines ${ }^{2}$ advise gene panel testing if: the patient is under 50 years of age; if there are multiple affected individuals within a family; or if there is dysplasia within any of the polyps.

Methods A database of patients with SPS according to the WHO 2019 criteria $^{3}$ was established at the Oxford University Hospitals NHS Trust. Data collection began in 2010 and in total there are 192 SPS patients. The results of any patients sent for genetic testing were analysed.

Results Out of 192 patients, 76 underwent genetic testing. The majority were tested for a hereditary colorectal cancer panel including MUTYH, APC, PTEN, SMAD4, BMPR1A, STK11 and Lynch syndrome mismatch repair genes. Of these, 14 had a positive genetic test result. Table 1 characterises patient with positive results.

Conclusions 7\% (14/192) of SPS patients were affected by heterozygous germline mutations, higher than in previous series ${ }^{1}$, including previously unreported associations with CHEK2 and POLD1. This led to a change in management for patients or their families in seven cases. Only 57\% (8/14) of these patients would have been recommended for gene panel testing in the current BSG guidelines ${ }^{2}$. Detection of germline mutations could have significant impact on risk assessment and clinical management, including advice on extra-colonic surveillance in patients and their family members. 


\begin{tabular}{|c|c|c|c|c|}
\hline $\begin{array}{l}\text { Gene } \\
\text { affected }\end{array}$ & Mutation & $\begin{array}{l}\text { WHO } \\
\text { SPS } \\
\text { type }\end{array}$ & $\begin{array}{l}\text { Age at } \\
\text { diagnosis }\end{array}$ & Clinical outcome \\
\hline RNF43 & $\begin{array}{l}\text { c. } 471 \text { del G } \\
\text { Pathogenic } \\
\text { variant }\end{array}$ & ॥ & 68 & $\begin{array}{l}\text { Cascade genetic testing for at-risk } \\
\text { relatives }\end{array}$ \\
\hline $\begin{array}{l}\text { MUTYH } \\
\text { APC }\end{array}$ & $\begin{array}{l}\text { c.1187G }>\mathrm{A} \\
\text { Pathogenic } \\
\text { variant } \\
\text { c.646-4T>G } \\
\text { Uncertain } \\
\text { variant }\end{array}$ & 1 & 70 & $\begin{array}{l}\text { Cascade genetic testing for at-risk } \\
\text { relatives }\end{array}$ \\
\hline MUTYH & $\begin{array}{l}\text { c. } 1187 \mathrm{G}>\mathrm{A} \\
\text { Pathogenic } \\
\text { variant }\end{array}$ & ॥ & 32 & $\begin{array}{l}\text { Cascade genetic testing for at-risk } \\
\text { relatives }\end{array}$ \\
\hline SMAD4 & $\begin{array}{l}\text { c.455- } \\
2 \mathrm{~A}>\mathrm{G} \\
\text { Pathogenic } \\
\text { variant }\end{array}$ & 1 & 78 & $\begin{array}{l}\text { Upper GI endoscopic surveillance, } \mathrm{HHT} \\
\text { screening and cascade genetic testing for } \\
\text { at-risk relatives }\end{array}$ \\
\hline POLD1 & $\begin{array}{l}\text { c. } 946 \mathrm{G}>\mathrm{A} \\
\text { Pathogenic } \\
\text { variant }\end{array}$ & 1 & 70 & $\begin{array}{l}\text { Cascade genetic testing for at-risk } \\
\text { relatives }\end{array}$ \\
\hline CHEK2 & $\begin{array}{l}\text { c. } 1427 \mathrm{C}>\mathrm{T} \\
\text { Pathogenic } \\
\text { variant }\end{array}$ & I & 34 & $\begin{array}{l}\text { Annual PSA testing and cascade genetic } \\
\text { testing for at-risk relatives }\end{array}$ \\
\hline CHEK2 & $\begin{array}{l}\text { c.1100delC } \\
\text { Pathogenic } \\
\text { variant }\end{array}$ & 1 & 68 & $\begin{array}{l}\text { Moderate risk breast screening and } \\
\text { cascade genetic testing for at-risk } \\
\text { relatives }\end{array}$ \\
\hline MSH6 & $\begin{array}{l}\text { c. } 1054 \mathrm{G}>\mathrm{A} \\
\text { Uncertain } \\
\text { variant }\end{array}$ & 1 & 30 & No change \\
\hline MSH6 & $\begin{array}{l}\text { c. } 2398 \mathrm{G}>\mathrm{C} \\
\text { Uncertain } \\
\text { variant }\end{array}$ & 1 & 59 & No change \\
\hline MSH6 & $\begin{array}{l}\text { c. } 3026 \mathrm{~A}>\mathrm{T} \\
\text { Uncertain } \\
\text { variant }\end{array}$ & 1 & 36 & No change \\
\hline MSH2 & $\begin{array}{l}\text { c. } 835 \mathrm{C}>\mathrm{G} \\
\text { Uncertain } \\
\text { variant }\end{array}$ & 1 & 37 & No change \\
\hline APC & $\begin{array}{l}\text { c. } 3479 \mathrm{C}>\mathrm{A} \\
\text { Uncertain } \\
\text { variant }\end{array}$ & ॥ & 54 & No change \\
\hline APC & $\begin{array}{l}\text { c. } 2486 C>T \\
\text { Uncertain } \\
\text { variant }\end{array}$ & 1 & 38 & No change \\
\hline NTHL1 & $\begin{array}{l}\text { c. } 512 C>T \\
\text { Uncertain } \\
\text { variant }\end{array}$ & ॥ & 52 & No change \\
\hline
\end{tabular}

\section{REFERENCES}

1. Clendenning M, Young JP, Walsh MD, et al. Germline mutations in the polyposisassociated genes BMPR1A, SMAD4, PTEN, MUTYH and GREM1 are not common in individuals with serrated polyposis syndrome. PLoS ONE 2013;8:e66705.

2. Monahan KJ, Bradshaw N, Dolwani $\mathrm{S}$, et al. Guidelines for the management of hereditary colorectal cancer from the British Society of Gastroenterology (BSG)/ Association of Coloproctology of Great Britain and Ireland (ACPGBI)/United Kingdom Cancer Genetics Group (UKCGG). Gut 2020;69(3):411-444.

3. Rosty C, Brosens LAA, Nagtegaal ID. Serrated Polyposis. WHO Classification of Tumours. Digestive System Tumours, 2019.
Neurogastroenterology

\section{IS THE LOW FODMAP DIET EFFECTIVE IN THE LONG TERM? THE LARGEST MULTICENTRE PROSPECTIVE STUDY}

${ }^{1}$ Anupam Rej ${ }^{*}$, ${ }^{1}$ Rachel L Buckle, ${ }^{1}$ Christian C Shaw, 'Nick Trott, 'Sebastian Adu-Tei, ${ }^{2}$ Anurag Agrawal, ${ }^{2}$ Joanna Mosey, ${ }^{3}$ Katie Sanders, ${ }^{4}$ Rupert Allen, ${ }^{4}$ Sophie Martin, ${ }^{5}$ Aimee Newton, ${ }^{6}$ Kelly Robinson, ${ }^{6}$ David Elphick, ${ }^{1}$ Imran Aziz, ${ }^{1}$ David S Sanders. ${ }^{1}$ Academic Unit of Gastroenterology, Royal Hallamshire Hospital, Sheffield Teaching Hospital NHS Foundation Trust, Sheffield, UK; ${ }^{2}$ Doncaster and Bassetlaw Hospitals NHS Trust, Armthorpe Road, Doncaster, UK; ${ }^{3}$ University Hospital Lewisham, Lewisham High Street, London, UK; ${ }^{4}$ Bradford Teaching Hospitals NHS Foundation Trust, Duckworth Lane, Bradford, UK; ${ }^{5}$ York Teaching Hospital NHS Foundation Trust, Wigginton Road, York, UK; ${ }^{6}$ Chesterfield Royal Hospital NHS Foundation Trust, Calow, Chesterfield, UK

\subsection{6/gutjnl-2020-bsgcampus.58}

Introduction The low FODMAP diet (LFD) has been demonstrated to be effective in managing the symptoms of irritable bowel syndrome (IBS) in the short term. However, data remains limited on the long-term effects of this dietary therapy. The aim of this study was to assess the long-term effect of the LFD on symptom management and adherence.

Methods Patients with IBS who had received LFD advice between 2012-2019 were prospectively recruited at 7 centres in the United Kingdom. Participants were invited to complete dietary questionnaires assessing the LFD at long term follow up ( $>6$ months). Symptoms were assessed using a modified gastrointestinal symptom rating scale $(0$, none; 1 , mild; 2 , moderate; 3, severe).

Results 589 patients were approached, with 154 participants completing the study $(76 \%$ female, mean age $51 \pm 15$ years). The mean duration of follow up following initiation of the LFD was $42 \pm 28$ months. A statistically significant improvement in abdominal pain $(2.3 \pm 0.8$ vs $1.2 \pm 0.9, \quad \mathrm{p}<0.001)$, abdominal bloating/distention $(2.3 \pm 0.8$ vs $1.4 \pm 1.0, \mathrm{p}<0.001)$ and bowel urgency $(2.0 \pm 1.1$ vs $1.3 \pm 1.0, \mathrm{p}<0.001)$ was noted following the LFD at long term versus baseline. $78 \%(n=120)$ of individuals reported following an adapted LFD at long term follow up. 60\% $(\mathrm{n}=92)$ reported grains (wheat, rye, barley) as a trigger for their symptoms, with $64 \%(\mathrm{n}=98)$ purchasing gluten or wheat free products in the long term.

Conclusion This is the largest study demonstrating the efficacy of the LFD in the long term for individuals with IBS. Adherence to an adapted LFD appears to be good in the long term, with the majority of individuals reporting grains as a trigger and purchasing gluten or wheat free products to manage their symptoms.

\section{MRI METHODS TO DEFINE COLONIC FUNCTION IN HEALTH AND CONSTIPATION}

${ }^{1}$ Victoria Wilkinson-Smith*, ${ }^{1}$ Caroline Hoad, ${ }^{2}$ David Atkinson, ${ }^{1} L u c a$ Marciani, ${ }^{1}$ Maura Corsetti, ${ }^{3}$ S Mark Scott, ${ }^{2}$ Stuart Taylor, ${ }^{1}$ Penny Gowland, ${ }^{1}$ Robin Spiller. ${ }^{1}$ NIHR Nottingham Biomedical Research Centre, University of Nottingham, Nottingham, UK: ${ }^{2}$ Centre For Medical Imaging, UCL, UK, London, UK; ${ }^{3}$ Neurogastroenterology Group, QMUL, London, UK

\subsection{6/gutinl-2020-bsgcampus.59}

Background RECLAIM is a multicentre study examining patients with functional constipation (FC) and IBS with constipation (IBS-C), along with healthy volunteers (HV) to correlate MRI findings with those from colonic manometry, and 